\title{
Are kids having a rough time of it in sports?
}

\section{Dennis J Caine}

Participation in children's and youth sports is increasingly popular and widespread in western culture. In the USA, for example, more than 30 million children participate in sports each year. ${ }^{1}$ Trends over recent decades include increased numbers of participants, particularly girls, increased duration and intensity of training, earlier specialisation and year-round training, and increased difficulty of skills practised. In addition, children and adolescents are increasingly visiting wilderness recreational destinations and participating in a growing number of "extreme sports" such as skate boarding, BMX, mountain biking and rock climbing. Physical activity has important and wideranging health benefits. Indeed, no one has disputed it as being the solution to the biggest public health problem of the 21st century. ${ }^{2}$ In particular, in children physical activity increases physical fitness (both cardiorespiratory fitness and muscular strength), reduces body fatness, improves cardiovascular and metabolic disease risk profiles, enhances bone health and reduces symptoms of depression and anxiety. ${ }^{3}$

\section{BALANCING RISKS AND BENEFITS}

Engaging in sports and recreational activities at a young age also involves a risk of injury. ${ }^{4}$ Young athletes may be particularly vulnerable to injury due to such growth-related factors as the adolescent growth spurt, susceptibility to growth plate injury, differences in maturity status, longer recovery and differing physiological response after concussion, and non-linearity of growth. ${ }^{6}$ They might also be at risk because of immature or underdeveloped coordination, skills and perception. ${ }^{7}$ Concern has also been raised regarding the young female athlete who may be at increased risk of non-contact anterior cruciate ligament injuries due to such factors as anatomy, hormones and menstrual cycle, neuromuscular characteristics, muscle strength and flexibility. ${ }^{8}$ The frequent and intensive training and competition of young athletes now may

Correspondence to: Dr D J Caine, Department of Physical Education, Exercise Science and Wellness, University of North Dakota, Grand Forks, ND 582038235, USA; denniscaine@mail.und.edu create conditions under which these potential risk factors can more readily exert their influence.

The increased sports and recreational activity of children from an early age and continued through the years of growth, against a background of their unique vulnerability to injury, gives rise to concern about the risk and severity of injury and other health-related problems. Recent data suggest that the risk of sport and recreation injury is high and constitutes a significant public health burden. For example, in a recent report, ${ }^{9} 65 \%$ of all sports, recreation and exercise-related injury visits to US emergency departments in 2000 and 2001 (out of 4.3 million visits) were sustained by individuals 19 years of age or younger. Sports, recreation and exercise-related injuries were the most common cause of paediatric injuries in other surveys, accounting for $19-29 \%$ of all injuries in this population. ${ }^{10-12}$ In addition to the immediate healthcare costs, these injuries may have long-term consequences on the musculoskeletal system, resulting in reduced levels of physical activity and, therefore, reduction in wellness.

Other health-related problems that have been associated with sports participation include disordered eating, obesity, sports-related violence and the use of steroids. For example, concern has been raised that participation in organised sport is a risk factor for anabolic steroid use among adolescents, ${ }^{13}$ and that participation in leanness sports, in particular, might predispose young athletes to disordered eating. ${ }^{14}$ There is also concern that overweight and obese young athletes are at an increased risk of sport-related injury ${ }^{15}$ and that sport-related violence (hazing, foul play and brawling) in youth sports can result in both physical and emotional injury. ${ }^{16}$

Are kids having a rough time of it in sports? The objective of this theme issue is to highlight a range of safety and other healthrelated concerns affecting young athletes by compiling commissioned reviews and original investigations by international experts in the areas of sports medicine, injury epidemiology and sport science.
POTENTIALLY LETHAL CONDITIONS AND LONG-TERM OUTCOMES

The issue begins with two articles focused on an epidemiological perspective of potentially lethal sport-related conditions including direct catastrophic and heatrelated injuries. Most of what we know about the rate of these injuries has been derived from high school data provided by the National Center for Catastrophic Sports Injury Research (NCCSIR) at the University of North Carolina. ${ }^{17}$ We learn from Marshall ${ }^{18}$ (heat injuries, see page 8 ) and Zemper ${ }^{19}$ (direct catastrophic injuries, see page 13) that heat injuries and direct catastrophic sports injuries (a sport injury that results in a fatality, a non-fatal brain or spinal cord injury, or skull or spinal fracture) are relatively rare events, and that the risk of these injuries varies by sport and gender. However, these injuries may be underreported because the NCCSIR is influenced by media coverage and depends on volunteers. There are also many sports and recreational activities that the NCCSIR does not cover. Regardless of the frequency, however, even one catastrophic injury involving a young athlete is one too many, especially given that these injuries are largely preventable. The authors of these two articles underscore the need for further research to identify risk factors and evaluate intervention programmes for catastrophic injuries.

In the third paper of this section, Maffulli and colleagues ${ }^{20}$ review the long-term outcomes of youth sports injury (see page 21). Limited data arising from a few sports indicate the potential for injury to cause some young athletes to drop out of their sport, either for the season or permanently. Of considerable concern are the follow-up studies of young and former athletes that indicate a relatively high risk of osteoarthritis subsequent to traumatic joint injury (eg, meniscus tear). The authors emphasise the need for follow-up research to illuminate better the long-term outcomes of physeal injuries and spine conditions that commonly affect young athletes.

\section{UNHEALTHY BEHAVIOURS}

Three articles in this theme issue address unhealthy behaviours among young athletes, including steroid use, violence in youth sports and disordered eating. ${ }^{21-23}$ From the comprehensive submissions of Harmer $^{21}$ (steroid use, see page 26), Fields and colleagues ${ }^{22}$ (sport-related violence, see page 32) and Martinsen and co-workers ${ }^{23}$ 
(disordered eating, see page 70) we learn that the extent of steroid use and disordered eating among young athletes may be less than formerly believed, and that sports involvement may actually be associated with a protective effect against these behaviours. In fact, steroid use and disordered eating may rather relate to a general matrix of deviant behaviour found in the adolescent population. Similarly, Fields et $a^{22}$ suggest that sport-related violence including hazing, brawling and foul play may actually be representative of a larger social and public health problem of interpersonal violence. Their review shows that sports-related violence occurs among youth athletes of all ages and in a variety of sports; however, no incidence tracking method has been developed. The authors of all three articles agree that monitoring the magnitude and distribution of sports-related steroid use, disordered eating and interpersonal violence are essential first steps towards a reduction in these behaviours.

\section{UNIQUE INJURY RISKS}

Two submissions deal with unique injury risks associated with female and with overweight athletes: Knowles ${ }^{24}$ (injury epidemic in girls' sports, see page 38 ) and $\mathrm{McHugh}^{25}$ (the oversized athlete, see page 45). From Knowles' ${ }^{24}$ contribution we learn that the young female athlete is characterised by lower injury rates in almost all sports compared with young male athletes. However, the data show that young female athletes are at increased risk of knee and non-contact anterior cruciate ligament injuries relative to their male counterparts. Girls also have higher rates of surgery for the same injuries as young boys. In contrast, the overweight athlete is shown to be at greater risk of injury, particularly ankle sprains. However, further research using prospective study designs and exposurebased determination of injury rates is necessary to confirm this relationship.

The next two articles address injuries that occur in wilderness and resistancetraining venues. Heggie ${ }^{26}$ provides an overview of wilderness injuries (see page 50), including those occurring in popular outdoor destinations, expeditions and outdoor programmes and national parks. Although denominator data are lacking, the reader is provided with a sobering account of largely preventable injuries, including fatalities, which have occurred in these settings. In contrast, the review by Faigenbaum and $\mathrm{Myer}^{27}$ of resistance training injuries (see page 56), based largely on data from multiple resistance training intervention studies, suggests a relatively safe training environment where few injuries occur. However, welldesigned prospective epidemiological studies of young athletes involved in resistance training are lacking.

\section{INJURY PREVENTION}

Our thematic issue concludes with Emery $^{28}$ describing a scientific approach to injury prevention in children's and youth sports (see page 64). Evidence is provided for the increasing need to focus on evaluation research, and methodological considerations are necessary to provide scientific evidence appropriately and accurately to inform practice and policy in injury prevention in youth sport. Injury prevention in youth sport is becoming a great public health priority given the longterm health impact and decreased levels of physical activity following sport injuries.

\section{CONCLUSIONS}

Throughout this theme issue a public health approach was used to acquaint the reader with available information on the incidence, severity, aetiology and prevention of selected sports injury and healthrelated conditions. Despite evidence that indicates that catastrophic sports injuries are relatively infrequent occurrences, every effort must be made to continue to prevent unnecessary injuries. For example, American football players should be educated to avoid spearing with the head when blocking and tackling, and coaches should be educated on the proper procedures and precautions when practising or playing in the heat. ${ }^{17}$ Due to serious concerns and continued controversy regarding concussion in young athletes, Guskiewicz and McLeod will provide a comprehensive review on "Paediatric sport-related concussion" in an upcoming issue of this journal.

Despite the evidence that disordered eating and steroid use may be no greater in young athletes than controls, the prevalence is still unacceptable and it remains critical that those responsible for organising and administering youth sports take every precaution to educate athletes regarding the adverse effects of these unhealthy behaviours. In addition, although the overall risk of injury for girls may not be as great as for boys in most sports, every effort should be made to prevent unnecessary injuries in girls' sports. Continued efforts to protect girls against knee injuries is also clearly very much in order.

It is also evident that denominatorbased descriptive data are needed for many sports, including "extreme" sports and wilderness activities, as well as for injuries related to interpersonal violence in sport. In this regard, the implementation of large-scale, exposure-based injury surveillance systems is required given that most children's and youth sports lack good quality descriptive data, the fundamental building blocks of epidemiology, without which the capacity to conduct meaningful analytical studies is severely compromised. ${ }^{29} 30$ The importance of longitudinal data collection for obtaining an accurate picture of injury risk and risk factors, and for determining the long-term effects of youth sports injury, cannot be overemphasised. The application of epidemiological methods to this ongoing research will help to provide answers to the questions of how to prevent sports injuries and adverse sport-related health conditions effectively.

Acknowledgements: The author is grateful that leading researchers in their fields agreed to help with this special issue and is very pleased with the quality of the informative reports that they have contributed. The author wishes to thank the following individuals for their invaluable editorial input: Caroline Caine, PhD; Paul McCrory, MBBS, PhD; Jiri Dvorak, MD, PhD; Peter Harmer, PhD, MPH, ATC; Warren Howe, MD; Fred Mueller, PhD; and Steven Stovitz, MD.

Competing interests: None.

Provenance and peer review: Commissioned; externally peer reviewed.

Br J Sports Med 2010;44:1-3. doi:10.1136/bjsm.2009.069484

\section{REFERENCES}

\section{National Institute of Arthritis and} Musculoskeleletal and Skin Diseases. Childhood sports injuries and their prevention: a guide for parents with ideas for kids. NIH Pub 06-4821, August 2006. http://www.niams.nih.gov/Health Info/ Sports_Injuries/child_sports_injuries.asp laccessed 31 Oct 2009).

2. Blair SN. Physical inactivity: the biggest public health problem of the 21st century. Br J Sports Med 2009;43:1-2.

3. US Department of Health and Human Services Physical activity advisory committee report. Washington, DC: US Department of Health and Human Services, 2008. http://www.health.gov/ PAGuidelines/Report/ (accessed 31 Oct 2009).

4. Caine D, Maffulli N, Caine C. Epidemiology of injury in child and adolescent sports: injury rates, risk factors, and prevention. Clin Sports Med 2008;27:19-50.

5. Caine DJ, Maffulli N. The epidemiology of children's individual sport injuries: an important area of medicine and sport science research. In: Epidemiology of pediatric sports injuries: individual sports. Med Sport Sci. Basel: Karger, 2005;48:1-7.

6. McCrory P, Meeuwisse W, Johntson K, et al. Consensus statement on concussion in sport: the $3 \mathrm{rd}$ International Conference on Concussion in Sport Held in Zurich, November 2008. Br J Sports Med 2009;43(Suppl 1):i76-84. doi: 10:1136/ bjsm.2009.058248

7. National Center for Injury Prevention and Control. CDC Injury Research Agenda 2009-2018. Atlanta (GA): Centers for Disease Control and Prevention. http://www.cdc.gov/injury/ ResearchAgenda/CDC Injury_Research_Agenda-a. pdf (accessed 31 Oct 2009). 
8. Griffin LY, Albohm MJ, Arendt EA, et al. Understanding and preventing noncontact anterior cruciate ligament injuries: a review of the Hunt Valley II meeting, January 2005. Am J Sports Med 2006; 34:1512-32.

9. Centers for Disease Control and Prevention Morbidity and Mortality Weekly Report. Non-fatal sports- and recreation-related injuries treated in emergency departments, United States, July 2000June 2001. MMWR Wkly 2002;51:736-9. http:// www.cdc.gov/mmwr/preview/mmwrhtml/ mm5133a2.htm (accessed 31 0ct 2009).

10. Simon TD, Bublitz MS, Hambidge SJ. External causes of pediatric injury-related emergency department visits in the United States. Acad Emerg Med 2004;11:1042-8.

11. Burt CW, Overpeck MD. Emergency visits for sportsrelated injuries. Ann Emerg Med 2001;37:301-8.

12. Demsey RL, Layde PM, Laud PW, et al. Incidence of sports and recreation related injuries resulting in hospitalization in Wisconsin in 2000. Inj Prev 2005;11:91-6.

13. Yesalis C, Bahrke M. Doping among adolescent athletes. Bailliére's Best Pract Res Clin Endocrinol Metab 2000;14:25-35.
14. Sundgot-Borgen J. Risk and trigger factors for the development of eating disorders in female elite athletes. Med Sci Sports Exerc 1994;26:414-19.

15. Tyler T, McHugh M, Mirabella M, et al. Risk factors for noncontact ankle sprains in high school football players. Am J Sports Med 2006;34:471-5.

16. Fields SK, Collins CL, Comstock RD. Conflict on the courts. A review of sports-related violence literature. Trauma, Violence, Abuse 2007;8:359-69.

17. National Center for Catastrophic Sports Injury Research (NCCSIR). http://www.unc.edu/depts/ nccsi/ (accessed 31 October 2009).

18. Marshall SW. Heat injury in youth sport. Br J Sports Med 2010;44:8-12.

19. Zemper ED. Catastrophic injuries among young athletes. Br J Sports Med 2010;44:13-20.

20. Maffulli N, Longo UG, Gougoulias N, et al. Long-term health outcomes of youth sports injuries. Br J Sports Med 2010;44:21-5.

21. Harmer PA. Anabolic-androgenic steroid use among young male and female athletes: is the game to blame? Br J Sports Med 2010;44:26-31.

22. Fields SK, Collins CL, Comstock RD. Violence in youth sports: hazing, brawling, and foul play. $\mathrm{Br} J$ Sports Med 2010;44:32-7.
23. Martinsen M, Bratland-Sanda S, Eriksson AK, et al. Dieting to win or to be thin? A study of dieting and disordered eating among adolescent elite athletes and non-athlete controls. Br J Sports Med 2010:44:70-6.

24. Knowles SB. Is there an injury epidemic in girls' sports? Br J Sports Med 2010;44:38-44.

25. McHugh MP. Oversized young athletes: a weighty concern. Br J Sports Med 2010;44:45-9.

26. Heggie TW. Pediatric and adolescent sport injury in the wilderness. Br J Sports Med 2010:44:50-5.

27. Faigenbaum AD, Myer GD. Resistance training among young athletes: safety, efficacy and injury prevention effects. Br J Sports Med 2010;44:56-63.

28. Emery CA. Injury prevention in pediatric sport-related injuries: a scientific approach. Br J Sports Med 2010;44:64-9.

29. Harmer PA. Conclusions and further research. In Caine DJ, Harmer PA, Schiff MA, eds. Epidemiology of injury in Olympic sports. The Encyclopaedia of Sports Medicine. An IOC Medical Commission Publication. West Sussex, UK: Wiley-Blackwell Publishers, 2010:500-7

30. Caine D, Caine C, Maffulli N. Incidence and distribution of pediatric sport-related injuries. Clin J Sport Med 2006;16:500-13. 